Published in final edited form as:

J Org Chem. 2018 September 21; 83(18): 11323-11326. doi:10.1021/acs.joc.8b01544.

\title{
Synthesis of 8-Hydroxygeraniol
}

\author{
Francesca M. Ippoliti ${ }^{\dagger}$, Joyann S. Barber ${ }^{\dagger}$, Yi Tang, and Neil K. Garg ${ }^{*}$ \\ Department of Chemistry and Biochemistry, University of California, Los Angeles, California \\ 90095, United States
}

\section{Abstract}

An operationally simple protocol for the conversion of geranyl acetate to 8-hydroxygeraniol is reported. The convenient two-step procedure relies on an efficient, chemo-and regioselective $\mathrm{SeO}_{2}$-promoted oxidation, followed by straightforward deacetylation. This facile means to prepare 8-hydroxygeraniol is expected to enable biosynthetic studies pertaining to thousands of monoterpene indole alkaloids.

\section{Graphical Abstract}

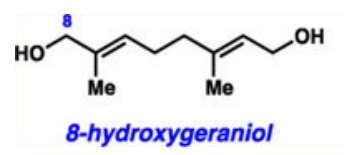

Precursor to $>3,000$ monoterpene indole alkaloids

\begin{abstract}
Monoterpene indole alkaloids (MIAs) have provided chemists and biologists with the inspiration to pursue countless scientific endeavors. ${ }^{1-4}$ To date, over 3000 MIAs have been discovered, many of which possess striking biological activity. Select examples of MIAs are the notorious poison strychnine (1) and the life-changing anticancer drug vinblastine (2), both of which are shown in Figure 1. All MIAs are prepared by nature through a remarkable biosynthetic pathway, which has been under investigation for decades. ${ }^{1,5-11}$
\end{abstract}

This Note focuses on 8-hydroxygeraniol (3, Figure 1), an early biosynthetic precursor to MIAs. 8-Hydroxygeraniol (3) is made biosynthetically through a controlled enzymatic oxidation of geraniol ${ }^{6}$ before being elaborated to nepetalactol (4). ${ }^{12}$ Many further biosynthetic manipulations ultimately give rise to strictosidine (5), the last common biosynthetic precursor to all MIAs. Given the relative simplicity of $\mathbf{3}$ compared to its successors in the biosynthetic pathway (e.g., 5), $\mathbf{3}$ has been used to enable several biosynthetic studies, including the biosynthesis of nepetalactol (4) ${ }^{13,14}$ and the biosynthesis of strictosidine (5). ${ }^{15}$

\footnotetext{
*Corresponding Author neilgarg@chem.ucla.edu.

$\dagger$ F.M.I. and J.S.B. contributed equally.

ASSOCIATED CONTENT

Supporting Information

The Supporting Information is available free of charge on the ACS Publications website at DOI: 10.1021/acs.joc.8b01544.

${ }^{1} \mathrm{H}$ NMR and ${ }^{13} \mathrm{C}$ NMR spectra for compounds $\mathbf{1 2}$ and $\mathbf{3}$ (PDF)

The authors declare no competing financial interest.
} 
Several synthetic approaches to 8-hydroxygeraniol (3) have been reported in the literature (Figure 2). The earliest reports appeared back-to-back in 1970, where multistep synthetic routes were developed beginning from either levulinaldehyde $(6)^{16}$ or dehydrolinalool (7). ${ }^{17}$ An alternative strategy was reported by Williams and Lin, which involved photocycloaddition of $\mathbf{8}$ and $\mathbf{9}$, with subsequent elaboration using a thermolysis/Cope rearrangement strategy. ${ }^{18}$ Perhaps the most direct approach relies on the use of geranyl acetate (10) as the starting material. In this regard, Kobayashi has reported a procedure for the $\mathrm{C} 8$-oxidation of $\mathbf{1 0}$ using stoichiometric $\mathrm{SeO}_{2}$, which proceeds in low yields and with extensive overoxidation to the corresponding enal. ${ }^{19}$ Around the same time, Sharpless reported a similar protocol that relies on catalytic $\mathrm{SeO}_{2}$ and stoichiometric t-butyl hydroperoxide. ${ }^{20}$ This procedure, which has subsequently been repeated with similar results, ${ }^{21}$ leads to a significant recovery of the starting material ${ }^{20}$ with some minimization of the overoxidation byproduct (i.e., $45 \%$ yield of the desired alcohol and 19\% enal ${ }^{21}$ ). A promising biocatalytic approach to 8-hydroxyger- aniol using a cytochrome $\mathrm{P} 450$ has also been described, ${ }^{21}$ although it has yet to be rendered practical for material throughput.

One further point regarding 8-hydroxygeraniol (3) and its naming should be noted. Throughout the aforementioned literature and other sources, the compound is often referred to as "10-hydroxygeraniol" instead (Figure 3). ${ }^{6,7,12,13,16-19}$ We believe this is a simple nomenclature error that has propagated for many decades. Similarly, 8-oxogeranial (11), the biosynthetic successor to 8-hydroxygeraniol (3), has been referred to as "10oxogeranial." 7,12,22 From a nomenclature standpoint, this is also incorrect. We suggest the chemical and biosynthetic community use the "8-" prefix going forward for 8hydroxygeraniol to minimize confusion, as this is consistent with IUPAC standards where " 8 " should reflect the longest carbon chain in the molecule, with $\mathrm{C} 8$ being the trans substituent on the alkene. ${ }^{23,24}$ Additionally, the " 8 -" prefix is accepted according to various enzymology resources. ${ }^{25,26}$

With the aim of developing a practical procedure for the preparation of 8-hydroxygeraniol (3) to enable our biosynthetic studies, ${ }^{14}$ we opted to pursue the chemo- and regioselective allylic oxidation of geranyl acetate (10), shown in Figure 2, as a starting point. Select results from our efforts to reproduce and optimize the catalytic $\mathrm{SeO}_{2}$ oxidation procedure are provided in Table 1 . As shown in entries 1 and 2 , the oxidation could be performed at $0{ }^{\circ} \mathrm{C}$. After $5 \mathrm{~h}$, significant amounts of unreacted geranyl acetate (10) remained (entry 1). However, longer reaction times at $0{ }^{\circ} \mathrm{C}$ showed promise for increasing the conversion (entry 2). For the sake of developing a more convenient protocol that would not require cooling for extended periods of time, we attempted the oxidation at $23{ }^{\circ} \mathrm{C}$. After $30 \mathrm{~min}$ or $1 \mathrm{~h}$, significant recovery of unreacted substrate $\mathbf{1 0}$ was observed (entries 3 and 4, respectively). When the reaction was performed for $1.5 \mathrm{~h}$, a more desirable ratio was obtained (entry 5), with the desired product $\mathbf{1 2}$ being formed in $61 \%$ yield. At longer reaction times of $5 \mathrm{~h}$, substrate $\mathbf{1 0}$ could be fully consumed, however, competitive overoxidation to enal $\mathbf{1 3}$ was observed (entry 6). Overall, entry 5 conditions were deemed ideal because of the convenience of the experimental protocol $\left(23^{\circ} \mathrm{C}, 1.5 \mathrm{~h}\right)$ and the optimal yield of $\mathbf{1 2}$ obtained. 
With practical reaction conditions in hand for the efficient oxidation of geranyl acetate (10), we performed the preparation of 8-hydroxygeraniol (3) on a $3 \mathrm{mmol}$ scale, as shown in Figure 4. $\mathrm{SeO}_{2}$-promoted oxidation of $\mathbf{1 0}$ proceeded smoothly under our optimized conditions in just $1.5 \mathrm{~h}$ at $23{ }^{\circ} \mathrm{C}$. This gave the desired C8-hydroxylated product 12 in $64 \%$ isolated yield. Subsequent treatment of $\mathbf{1 2}$ with $\mathrm{K}_{2} \mathrm{CO}_{3}$ in methanol at $23{ }^{\circ} \mathrm{C}$ smoothly delivered 8-hydroxygeraniol (3) in $83 \%$ yield after flash column chromatography. This exceedingly simple protocol can be used to synthesize multimmol quantities of $\mathbf{3}$.

In summary, we have developed a simple and convenient procedure to synthesize 8hydroxygeraniol (3). The procedure involves a regio- and chemoselective oxidation, followed by methanolysis. Both transformations are performed at ambient temperature and can be used to easily access multimmol quantities of $\mathbf{3}$. We expect this protocol will enable biosynthetic investigations pertaining to thousands of monoterpene indole alkaloids.

\section{EXPERIMENTAL SECTION}

\section{Materials and Methods.}

Unless stated otherwise, reactions were conducted in flame-dried glassware under an atmosphere of nitrogen using anhydrous solvents (either freshly distilled or passed through activated alumina columns). All commercially obtained reagents were used as received unless otherwise specified. Geranyl acetate (10) and potassium carbonate were purchased from Alfa Aesar. Selenium dioxide and tert-butyl hydroperoxide solution ( $5.5 \mathrm{M}$ in decane, over 4 A molecular sieves) were obtained from Sigma-Aldrich. Reaction temperatures were controlled using an IKAmag temperature modulator, and unless stated otherwise, reactions were performed at $23^{\circ} \mathrm{C}$. Thin-layer chromatography (TLC) was conducted with EMD gel 60 F254 precoated plates $(0.25 \mathrm{~mm})$ and visualized using anisaldehyde staining. Silicycle Siliaflash P60 (particle size $0.040-0.063 \mathrm{~mm}$ ) was used for flash column chromatography. ${ }^{1} H$ NMR spectra were recorded on Bruker spectrometers (at $500 \mathrm{MHz}$ ) and are reported relative to the residual solvent signal. Data for ${ }^{1} H$ NMR spectra are reported as follows: chemical shift $(\delta \mathrm{ppm})$, multiplicity, coupling constant $(\mathrm{Hz})$, and integration. ${ }^{13} \mathrm{C}$ NMR spectra were recorded on Bruker spectrometers (at $125 \mathrm{MHz}$ ) and are reported relative to the residual solvent signal. Data for ${ }^{13} \mathrm{C}$ NMR spectra are reported in terms of chemical shift. IR spectra were obtained on a PerkinElmer UATR Two FT-IR spectrometer and are reported in terms of frequency of absorption $\left(\mathrm{cm}^{-1}\right)$. DART-MS spectra were collected on a Thermo Exactive Plus MSD (Thermo Scientific) equipped with an ID-CUBE ion source, a Vapur Interface (IonSense Inc.), and an Orbitrap mass analyzer. Both the source and MSD were controlled by Excalibur software v. 3.0. The analyte was spotted onto OpenSpot sampling cards (IonSense Inc.) using $\mathrm{CH}_{2} \mathrm{Cl}_{2}$ as the solvent. Ionization was accomplished using UHP He (Airgas Inc.) plasma with no additional ionization agents. The mass calibration was carried out using Pierce LTQ Velos ESI (+) and (-) ion calibration solutions (Thermo Fisher Scientific).

\section{Representative Procedure for Optimization of Oxidation (Table 1, Entry 3 as an Example).}

To a flame-dried $10 \mathrm{~mL}$ round-bottom flask equipped with a magnetic stir bar and selenium dioxide (23.4 mg, $0.20 \mathrm{mmol}, 0.4$ equiv) under $\mathrm{N}_{2}$ were added $\mathrm{CH}_{2} \mathrm{Cl}_{2}(2.5 \mathrm{~mL}, 0.20 \mathrm{M})$, 
tert-butyl hydroperoxide (5.5 $\mathrm{M}$ in decane, $0.29 \mathrm{~mL}, 1.58 \mathrm{mmol}, 3.1$ equiv), and geranyl acetate (10, $109 \mu \mathrm{L}, 0.509 \mathrm{mmol}, 1.0$ equiv). After the mixture was stirred for $30 \mathrm{~min}$ at $23{ }^{\circ} \mathrm{C}$, water $(2 \mathrm{~mL})$ and EtOAc $(10 \mathrm{~mL})$ were added, and the reaction was transferred to a separatory funnel. The layers were separated, and the organic layer was washed successively with deionized water $(2 \times 5 \mathrm{~mL})$, saturated aqueous NaHCO3 $(1 \times 5 \mathrm{~mL})$, deionized water $(1 \times 5 \mathrm{~mL})$, and brine $(1 \times 5 \mathrm{~mL})$. The organic layer was dried over $\mathrm{MgSO} 4$, filtered, and concentrated under reduced pressure. To the resulting crude product was added 1,3,5trimethoxybenzene ( $28.3 \mathrm{mg}, 0.33$ equiv) as an external standard. The ratio and yields were determined by ${ }^{1} \mathrm{H}$ NMR analysis.

\section{8-Hydroxygeranyl Acetate (12).}

To a flame-dried $100 \mathrm{~mL}$ round-bottom flask equipped with a magnetic stir bar and selenium dioxide (226 mg, $2.04 \mathrm{mmol}, 0.4$ equiv) under $\mathrm{N}_{2}$ were added $\mathrm{CH}_{2} \mathrm{Cl}_{2}(25 \mathrm{~mL}, 0.20 \mathrm{M})$, tertbutyl hydroperoxide (5.5 $\mathrm{M}$ in decane, $2.9 \mathrm{~mL}, 15.8 \mathrm{mmol}, 3.1$ equiv), and geranyl acetate (10, $1.09 \mathrm{~mL}, 5.09 \mathrm{mmol}, 1.0$ equiv). After the mixture was stirred for $1.5 \mathrm{~h}$ at $23^{\circ} \mathrm{C}$, the reaction mixture was concentrated under reduced pressure. The crude oil was transferred to a separatory funnel with EtOAc $(50 \mathrm{~mL})$. The organic layer was washed successively with deionized water $(2 \times 20 \mathrm{~mL})$, saturated aqueous $\mathrm{NaHCO}_{3}(1 \times 20 \mathrm{~mL})$, deionized water $(1 \times$ $10 \mathrm{~mL})$, and brine $(1 \times 10 \mathrm{~mL})$. The combined aqueous layers were back-extracted with EtOAc $(1 \times 80 \mathrm{~mL})$. The combined organic layers were dried over $\mathrm{Na}_{2} \mathrm{SO}_{4}$, filtered, and concentrated under reduced pressure. The resulting crude oil was purified via flash chromatography (6:1 $\rightarrow 2: 1$ hexanes/EtOAc) to afford 8-hydroxygeranyl acetate $(\mathbf{1 2}, 688 \mathrm{mg}$, $64 \%$ yield) as a colorless oil. 8-Hydroxygeranyl acetate (12): $R_{f} 0.43$ (2:1 hexanes/EtOAc); ${ }^{1} \mathrm{H}$ NMR (500 MHz, CDCl3) $\delta 5.39-5.31(\mathrm{~m}, 2 \mathrm{H}), 4.58(\mathrm{~d}, J=7.1,2 \mathrm{H}), 3.99(\mathrm{~s}, 2 \mathrm{H}), 2.17$ (dt, J = 7.4, 7.4, 2H), 2.11-2.07 (m, 2H), $2.05(\mathrm{~s}, 3 \mathrm{H}), 1.71(\mathrm{~s}, 3 \mathrm{H}), 1.66(\mathrm{~s}, 3 \mathrm{H}) ;{ }^{13} \mathrm{C}$ NMR (125 MHz, CDCl3) $\delta 171.4,141.9,135.4,125.4,118.8,69.0,61.6,39.2,25.8,21.2,16.5$, 13.8; IR (film) 3424, 2919, 2860, 1736, 1671, $1229 \mathrm{~cm}^{-1}$; HRMS-APCI $(\mathrm{m} / \mathrm{z})[\mathrm{M}+\mathrm{H}]^{+}$ calcd for $\mathrm{C}_{12} \mathrm{H}_{21} \mathrm{O}_{3}{ }^{+} 213.1485$, found 213.1478 . Spectral data match those previously reported. ${ }^{14}$

\section{8-Hydroxygeraniol (3).}

A flame-dried $50 \mathrm{~mL}$ round-bottom flask equipped with a magnetic stir bar was charged with 8-hydroxygeranyl acetate (12, $633 \mathrm{mg}, 2.98 \mathrm{mmol}, 1$ equiv) and methanol (19 mL, 0.16 M). Potassium carbonate ( $495 \mathrm{mg}, 3.58 \mathrm{mmol}, 1.2$ equiv) was added in one portion. After the mixture was stirred at $23{ }^{\circ} \mathrm{C}$ for $2.5 \mathrm{~h}$, the solvent was removed under reduced pressure, and the reaction mixture was transferred to a separatory funnel with deionized water (10 $\mathrm{mL})$. The aqueous layer was extracted with diethyl ether $(3 \times 20 \mathrm{~mL})$. The combined organic layers were washed successively with $0.5 \mathrm{M}$ aqueous $\mathrm{HCl}(1 \times 10 \mathrm{~mL})$, saturated aqueous NaHCO3 $(1 \times 10 \mathrm{~mL})$, brine $(1 \times 10 \mathrm{~mL})$, and deionized water $(1 \times 10 \mathrm{~mL})$. Next, the organic layers were dried over $\mathrm{MgSO}$, filtered, and concentrated under reduced pressure. The resulting crude oil was purified via flash chromatography (1:1 hexanes/EtOAc) to afford 8-hydroxygeraniol (3, $490 \mathrm{mg}, 83 \%$ yield) as a light yellow oil. 8-Hydroxygeraniol (3): $R_{f}$ $0.18\left(1: 1\right.$ hexanes/EtOAc); ${ }^{1} \mathrm{H}$ NMR $\left(500 \mathrm{MHz}, \mathrm{CDCl}_{3}\right) \delta 5.41-5.34(\mathrm{~m}, 2 \mathrm{H}), 4.14(\mathrm{~d}, J=$ 6.9, 2H), 3.98 (s, 2H), 2.17 (dt, J = 7.5, 7.1, 2H), 2.09-2.04 (m, 2H), 1.67 (s, 3H), 1.65 (s, $3 \mathrm{H}), 1.44$ (br s, 2H); ${ }^{13} \mathrm{C}$ NMR (125 MHz, $\left.\mathrm{CDCl}_{3}\right) \delta 139.1,135.3,125.6,123.9,68.9,59.4$, 
39.1, 25.8, 16.3, 13.8; IR (film) 3307, 2916, 2859, 1669, $999 \mathrm{~cm}^{-1}$; HRMS-APCI ( $\left.\mathrm{m} / \mathrm{z}\right)[\mathrm{M}$ $+\mathrm{H}]^{+}$calcd for $\mathrm{C}_{10} \mathrm{H}_{19} \mathrm{O}_{2}{ }^{+}$171.1380, found 171.1375. Spectral data match those previously reported. ${ }^{14}$

\section{Supplementary Material}

Refer to Web version on PubMed Central for supplementary material.

\section{ACKNOWLEDGMENTS}

The authors are grateful to the University of California, Los Angeles, the National Science Foundation (CBET1605877 to Y.T.), the Packard Foundation (Y.T.), the Foote Family (F.M.I.), and the Chemistry-Biology Interface training program (J.S.B., USPHS National Research Service Award 5T32GM008496-20) for financial support. These studies were supported by shared instrumentation grants from the NSF (CHE-1048804) and the NIH NCRR (S10RR025631).

\section{REFERENCES}

(1). O'Connor SE; Maresh JJ Chemistry and Biology of Monoterpene Indole Alkaloid Biosynthesis. Nat. Prod. Rep. 2006, 23, 532-547. [PubMed: 16874388]

(2). Pickens LB; Tang Y; Chooi Y-H Metabolic Engineering for the Production of Natural Products. Annu. Rev. Chem. Biomol. Eng. 2011, 2, 211-236. [PubMed: 22432617]

(3). O'Connor SE Strategies for Engineering Plant Natural Products: The Iridoid-Derived Monoterpene Indole Alkaloids of Catharanthus roseus In Methods in Enzymology; Hopwood DA, Ed.; Academic Press: 2012; Vol. 515, pp 189-206. [PubMed: 22999175]

(4). Pritchett BP; Stoltz BM Enantioselective Palladium- Catalyzed Allylic Alkylation Reactions in the Synthesis of Aspidosperma and Structurally Related Monoterpene Indole Alkaloids. Nat. Prod. Rep. 2018, 35, 559-574. [PubMed: 29658039]

(5). Pan Q; Mustafa NR; Tang K; Choi YH; Verpoorte R Monoterpenoid Indole Alkaloids Biosynthesis and its Regulation in Catharanthus roseus: A Literature Review. Phytochem. Rev. 2016, 15, $221-$ 250.

(6). Madyastha KM; Meehan TD; Coscia CJ Characterization of a Cytochrome P-450 Dependent Monoterpene Hydroxylase from the Higher Plant. Biochemistry 1976, 15, 1097-1102. [PubMed: 3209]

(7). Ikeda H; Esaki N; Nakai S; Hashimoto K; Uesato S; Soda K; Fujita T Acyclic Monoterpene Primary Alcohol: NADP ${ }^{+}$Oxidoreductase of Rauwolfia serpentina Cells: The Key Enzyme in Biosynthesis of Monoterpene Alcohols. J. Biochem. 1991, 109, 341-347. [PubMed: 1864846]

(8). Madyastha KM; Guarnaccia R; Baxter C; Coscia CJ S-Adenosyl-L-methionine: Loganic Acid Methyltransferase: A Carboxyl- Alkylating Enzyme from Vinca rosea. J. Biol. Chem. 1973, 248, 2497-2501. [PubMed: 4698228]

(9). Irmler S; Schroder G; St-Pierre B; Crouch NP; Hotze M; Schmidt J; Strack D; Matern U; Schroder $\mathrm{J}$ Indole Alkaloid Biosynthesis in Catharanthus roseus: New Enzyme Activities and Identification of Cytochrome P450 CYP72A1 as Secologanin Synthase. Plant J. 2000, 24, 797-804. [PubMed: 11135113]

(10). Stockigt J; Zenk MH Isovincoside (Strictosidine), the Key Intermediate in the Enzymatic Formation of Indole Alkaloids. FEBS Lett. 1977, 79, 233-237.

(11). Caputi L; Franke J; Farrow SC; Chung K; Payne RME; Nguyen T-D; Dang T-TT; Carqueijeiro IST; Koudounas K; de Bernonville TD; Ameyaw B; Jones DM; Vieira IJC; Courdavault V; O'Connor SE Missing Enzymes in the Biosynthesis of the Anticancer Drug Vinblastine in Madagascar periwinkle. Science 2018, 360, 1235-1239. [PubMed: 29724909]

(12). Krithika R; Srivastava PL; Rani B; Kolet SP; Chopade M; Soniya M; Thulasiram HV Characterization of 10-Hydroxygeraniol Dehydrogenase from Catharanthus roseus Reveals Cascaded Enzymatic Activity in Iridoid Biosynthesis. Sci. Rep. 2015, 5, 8258. [PubMed: 25651761] 
(13). Campbell A; Bauchart P; Gold ND; Zhu Y; De Luca V; Martin VJJ Engineering of a Nepetalactol-Producing Platform Strain of Saccharomyces cerevisiae for the Production of Plant Seco- Iridoids. ACS Synth. Biol. 2016, 5, 405-414. [PubMed: 26981892]

(14). Billingsley JM; DeNicola AB; Barber JS; Tang M-C; Horecka J; Chu A; Garg NK; Tang Y Engineering the Biocatalytic Selectivity of Iridoid Production in Saccharomyces cerevisiae. Metab. Eng. 2017, 44, 117-125. [PubMed: 28939278]

(15). Brown S; Clastre M; Courdavault V; O’Connor SE De novo Production of the Plant-derived Alkaloid Strictosidine in Yeast. Proc. Natl. Acad. Sci. U. S. A. 2015, 112, 3205-3210. [PubMed: 25675512]

(16). Escher S; Loew P; Arigoni D The Role of Hydroxygeraniol and Hydroxynerol in the Biosynthesis of Loganin and Indole Alkaloids. J. Chem. Soc. D 1970, 823-825.

(17). Battersby AR; Brown SH; Payne TG Preparation and Isolation of Deoxyloganin: Its Role as Precursor of Loganin and the Indole Alkaloids. J. Chem. Soc. D 1970, 827-828.

(18). Williams JR; Lin C Photocycloaddition of 2,5- Dihydrothiophen SS-Dioxides to a, $\beta$-Unsaturated Cyclic Anhydrides. Synthesis of 10-Hydroxygeraniol. J. Chem. Soc., Chem. Commun. 1981, 752-753.

(19). Inouye H; Ueda S-I; Uesato S-I; Kobayashi K Studies on Monoterpene Glucosides and Related Natural Products. XXXVII. Biosynthesis of the Iridoid Glucosides in Lamium amplexicaule, Deutzia crenata and Galium spurium var. echinospermon. Chem. Pharm. Bull. 1978, 26, 33843394.

(20). Umbreit MA; Sharpless KB Allylic Oxidation of Olefins by Catalytic and Stoichiometric Selenium Dioxide with tert-Butyl Hydroperoxide. J. Am. Chem. Soc. 1977, 99, 5526-5528.

(21). Bogazkaya AM; von Buhler CJ; Kriening S; Busch A; Seifert A; Pleiss J; Laschat S; Urlacher VB Selective Allylic Hydroxylation of Acyclic Terpenoids by CYP154E1 from Thermobifidafusca YX. Beilstein J. Org. Chem. 2014, 10, 1347-1353. [PubMed: 24991288]

(22). Geu-Flores F; Sherden NH; Courdavault V; Burlat V; Glenn WS; Wu C; Nims E; Cui Y; O'Connor SE An Alternative Route to Cyclic Terpenes by Reductive Cyclization in Iridoid Biosynthesis. Nature 2012, 492, 138-142. [PubMed: 23172143]

(23). IUPAC. Nomenclature of Organic Chemistry, Sections A, B, C, D, E, F, and H. Pergamon Press: Oxford, 1979.

(24). Acyclic Terpenes. In System of Nomenclature for Terpene Hydrocarbons; Advances in Chemistry Series; American Chemical Society: Washington, DC, 1955; Vol. 14, pp 12-14.

(25). Swiss Institute of Bioinformatics. ExPASy. ENZYME entry: EC https://enzyme.expasy.org/ EC71.14.14.83 (accessed June 18, 2018).

(26). Kyoto University Bioinformatics Center. KEGG. Enzyme 1.14.14.83. https://www.genome.jp/ dbget-bin/www_bget?ec:1.14.14.83 (accessed June 18, 2018). 


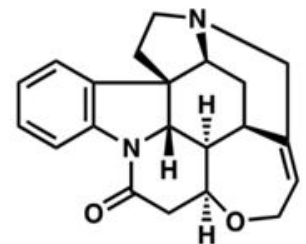

strychnine (1)

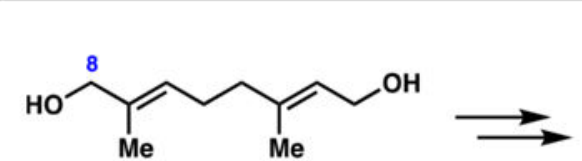

8-hydroxygeraniol (3)

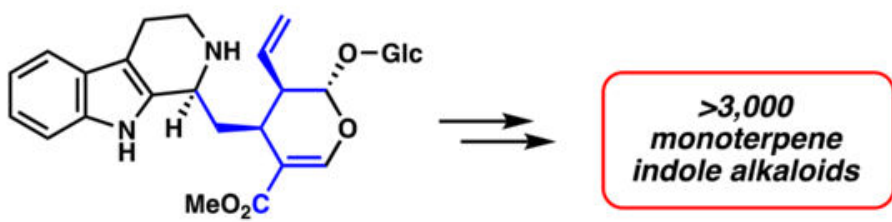

strictosidine (5)

vinblastine (2)

nepetalactol (4)
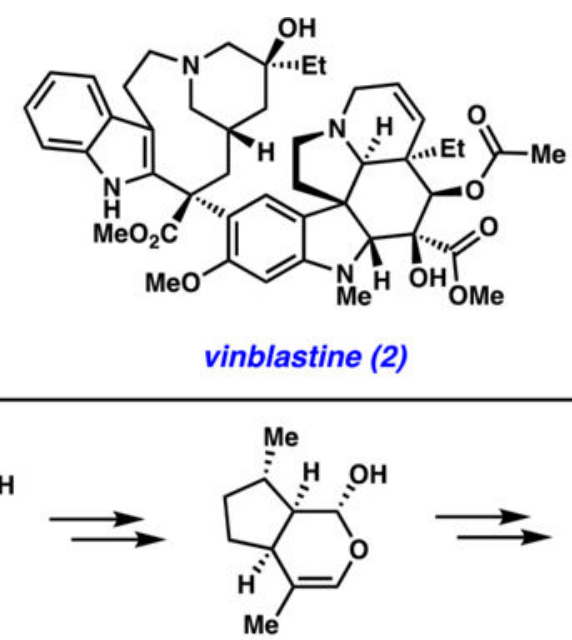

Figure 1.

Role of 8-hydroxygeraniol (3) in the biosynthesis of all monoterpene indole alkaloids, including strychnine (1) and vinblastine (2). 
<smiles>CC(=O)CCC=O</smiles>

6
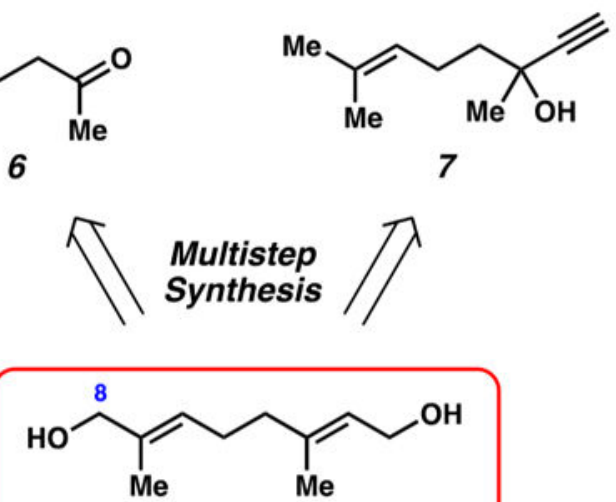

8-hydroxygeraniol (3)
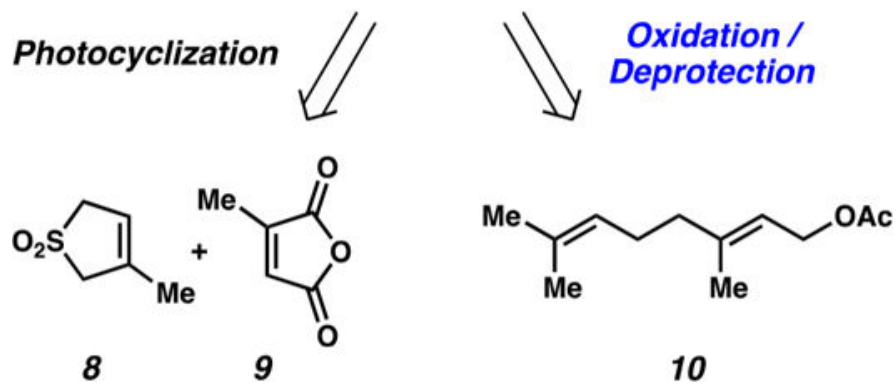

Figure 2.

Various approaches to 8-hydroxygeraniol (3). 


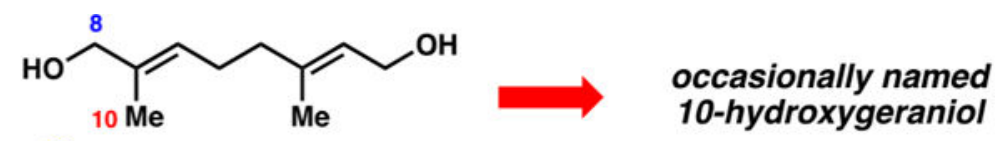

V 8-hydroxygeraniol (3)

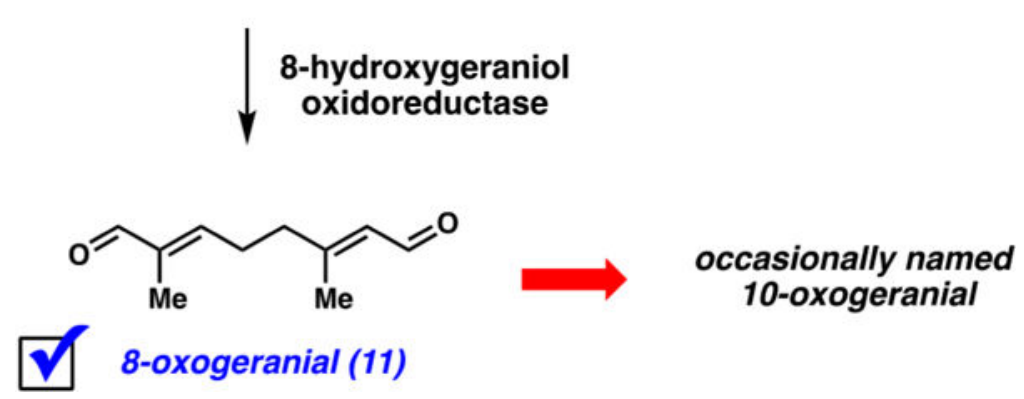

Figure 3.

Confusion surrounding the naming of 8-hydroxygeraniol (3) and its biosynthetic successor 8-oxogeranial (11). 

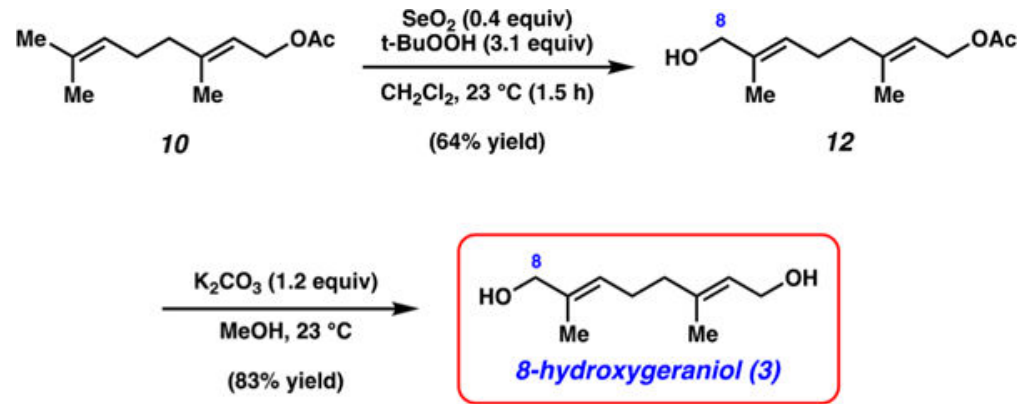

Figure 4.

Preparation of 8-hydroxygeraniol (3) on a $3 \mathrm{mmol}$ scale. 
Table 1.

Optimization of $\mathrm{SeO}_{2}$-Promoted Oxidation of $10^{a}$

\begin{tabular}{|c|c|c|c|c|}
\hline$Y_{M e}$ & 10 & $\begin{array}{r}\mathrm{SeO}_{2}(0 \\
t \text {-BuOOH }\end{array}$ & $\underset{\text { (quiv) }}{\stackrel{\text { M) }}{\text { equiv) }}}$ & Me \\
\hline Entry & Temperature & Time & Ratio of $10: 12: 13^{a}$ & Yield of $12^{a}$ \\
\hline 1 & $0^{\circ} \mathrm{C}$ & $5 \mathrm{~h}$ & $27: 68: 4$ & $43 \%$ \\
\hline 2 & $0^{\circ} \mathrm{C}$ & $7 \mathrm{~h}$ & $11: 82: 7$ & $57 \%$ \\
\hline 3 & $23^{\circ} \mathrm{C}$ & $0.5 \mathrm{~h}$ & $42: 55: 2$ & $43 \%$ \\
\hline 4 & $23^{\circ} \mathrm{C}$ & $1 \mathrm{~h}$ & $28: 67: 5$ & $57 \%$ \\
\hline 5 & $23^{\circ} \mathrm{C}$ & $1.5 \mathrm{~h}$ & $19: 73: 8$ & $61 \%$ \\
\hline 6 & $23^{\circ} \mathrm{C}$ & $5 \mathrm{~h}$ & $0: 52: 48$ & $24 \%$ \\
\hline
\end{tabular}

${ }^{a}$ Ratios and yields were determined by ${ }^{1} \mathrm{H}$ NMR analysis of the crude reaction mixtures $(1,3,5$-Trimethoxybenzene was used as an external standard). 